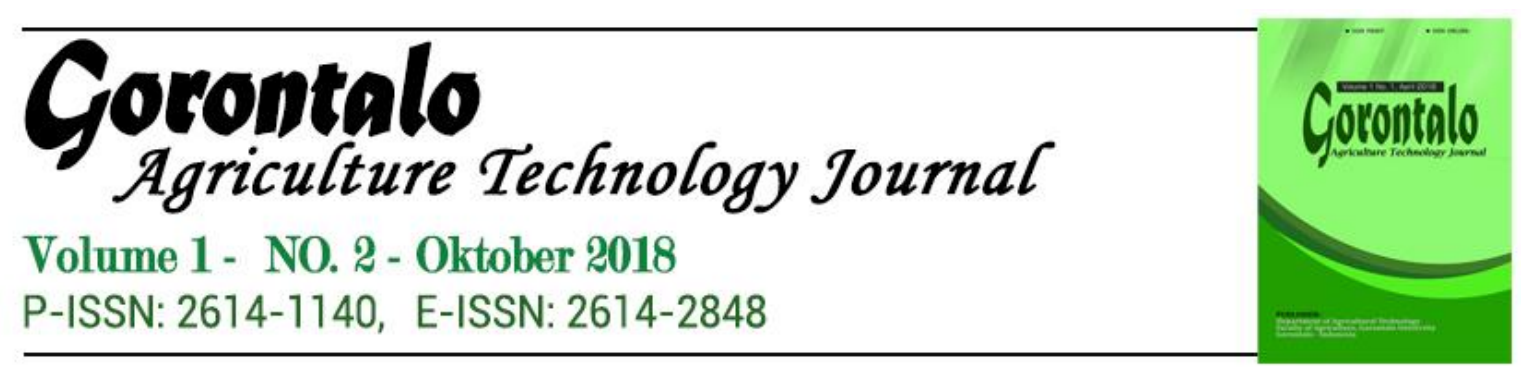

\title{
Pengaruh Kemasan Dan Pelilinan Terhadap Mutu Jeruk Pamelo Pangkep Merah Setelah Pengangkutan
}

\section{Effect Of Packaging And Waxing On Quality Of Red Pomelo Pangkep Citrus After Transportation}

\author{
Wanti Dewayani, Riswita Syamsuri, Nurjanani dan Warda Halil \\ Balai Pengkajian Teknologi Pertanian Sulawesi Selatan \\ wanti.abid@gmail.com
}

\begin{abstract}
Abstrak
Pengkajian ini dilaksanakan di lahan petani, Kabupaten Pangkajene Kepulauan (Pangkep), Sulawesi Selatan. Kemudian buah diangkut ke laboratorium BPTP untuk perlakuan dan pengamatan. Rancangan yang digunakan adalah Rancangan Petak Terpisah dengan 3 ulangan. Induk petak adalah perlakuan kemasan terdiri dari 2 faktor yaitu a) dos karton dan b) karung plastik (cara petani). Anak petak terdiri dari 2 faktor yaitu disekat dan tidak disekat dan anak-anak petak adalah pelilinan terdiri dari 2 faktor yaitu dililin dan tidak dililin. Pengamatan dilakukan pada saat sebelum dikirim di makassar dan setelah diangkut di Bogor. Pengamatan dilakukan terhadap berat buah, lingkar buah, kadar gula, kadar asam dan vitamin C. Dari hasil penelitian menunjukkan bahwa perlakuan yang terbaik pada buah jeruk Pamelo setelah pengangkutan dari Makassar ke Bogor adalah kemasan dos karton yang disekat dan dililin dengan susut bobot terkecil $(1,76-$ $1,95 \%)$, lebar buah normal $(14,5-19,3 \mathrm{~cm})$, kandungan vitamin C paling tinggi $(24,02-34,36 \%)$, kadar asam $(65,00-68,74 \%)$ dan kadar gula tinggi $\left(8,85-11,79\right.$ Brix $\left.^{\circ}\right)$. Perlakuan yang masih disukai rasanya oleh panelis setelah pengangkutan adalah jeruk pamelo yang dikemas dalam dos, disekat tanpa pelilinan, karung disekat baik dililin maupun tanpa dililin dengan tingkat kesukaan 55\%. Sedangkan aroma jeruk masih tetap baik setelah pengangkutan dan tidak berbeda nyata untuk semua perlakuan dengan tingkat kesukaan 67,5 \% - 85,00 \%. Penampilan yang paling disukai panelis setelah pengangkutan adalah perlakuan pelilinan yang dikemas dalam dos baik disekat maupun tidak disekat
\end{abstract}

Katakunci : jeruk; pamelo; kemasan; mutu, pelilinan. 


\begin{abstract}
This assessment was conducted in farmers' fields, Pangkajene District Islands (Pangkep), South Sulawesi. Then the fruit is transported to the BPTP laboratory for treatment and observation. The design used was a draft Separated plot with three replications. Main plot is the treatment of the packaging consists of two factors: a) carton and b) a plastic bag (the way farmers). Subplot consisted of two factors, namely insulated and not insulated and waxing plot is composed of two factors, namely waxing and not waxing. Observations were made at the time before it is sent in Makassar and after being transported in Bogor. Observations carried out on fruit weight, fruit circumference, total soluble sugar, acid and vitamin C. The results showed that The best treatment in citrus fruits Pummelo after transport from Makassar to Bogor is insulated carton packaging and waxed with the smallest weight loss (1.76 to 1.95\%), fruit width normal (14.5 to $19.3 \mathrm{~cm})$, the highest content of vitamin $C(24.02$ to $34.36 \%$ ), acid (65.00 \% to 68.74\%) and high sugar levels (8.85 to 11.79 Brix ${ }^{\circ}$. The treatment still preferred taste by panelists after the carriage is pamelo oranges are packed in a box, sealed without waxing, sealed sack both waxed or without waxed with a preference level of 55\%. Whereas the scent of pummelo is still good after the carriage and not significantly different for all treatments with a preference level of $67.5 \%-85.00 \%$. The most preferred appearance panelist after the transport is waxing treatments are packaged in either carton of insulated or not insulated.
\end{abstract}

Keywords: citrus; packaging; pomelo; Quality; Waxing. 


\section{PENDAHULUAN}

Jeruk besar (Citrus grandis L.) merupakan salah satu tanaman buah yang potensial untuk dikembangkan di Indonesia. Salah satu daerah pengembangan jeruk besar di Indonesia adalah Sulawesi Selatan. Saat ini, sentra produksi jeruk besar di Sulawesi Selatan tidak hanya di kabupaten Pangkep tetapi terus menyebar pada 20 kabupaten lainnya dengan produksi yang terus meningkat dari $9.493 \mathrm{t}$ pada tahun 2008 menjadi $14.161 \mathrm{t}$ pada tahun 2009 (BPS. 2010). dan pemasarannya sudah berkembang luas dan pangsa pasar terbesar adalah Pulau Jawa, meliputi Jawa Timur, Jawa Tengah, Yogyakarta, Jakarta dan Jawa Barat sebesar (61\%), Makassar (21\%) dan sisanya ke Kalimantan dan daerah Sulawesi lainnya (18\%) (Armiati, 2010).

Masalah utama usahatani pamelo adalah: (a) pembibitan (seleksi bibit/pohon induk belum optimal); (b) pemeliharaan (pemupukan belum sesuai ketersediaan hara dan kebutuhan tanaman, pemangkasan belum dilakukan, pengamatan kebun belum terjadwal, pengendalian hama/penyakit belum sesuai hama/penyakit sasaran; (c) pemasaran dilakukan secara borongan (belum ada sortasi/grading); (d) kelembagaan petani belum menjangkau agribisnis secara utuh, tetapi terfokus pada aspek produksi (Armiati, 2010). Disamping itu dalam pemasaran buah jeruk pamelo, tingkat kerusakan masih tinggi saat sudah sampai ke tempat pemasaran dengan tingkat kerusakan hingga $50 \%$.

Selama pengangkutan dan penyimpanan produk pertanian banyak mengalami kerusakan baik yang diakibatkan dari faktor eksternal seperti getaran maupun internal. Untuk menjaga agar terhindar dari kerusakan tersebut maka penggunaan kemasan sangat diperlukan (Mihindukulasuriya and Lim, 2014). Oleh karena itu dilakukan penelitian yang bertujuan pengaruh kemasan dan pelilinan terhadap mutu jeruk pamelo pangkep merah setelah pengangkutan.

\section{METODOLOGI}

Pengkajian ini dilaksanakan di lahan petani, Kabupaten Pangkajene Kepulauan (Pangkep), Sulawesi Selatan. Buah dipanen dan diangkut ke laboratorium BPTP untuk perlakuan dan pengamatan. Rancangan yang digunakan adalah Rancangan Petak Terpisah dengan 3 ulangan. Induk petak adalah perlakuan kemasan terdiri dari 2 faktor yaitu a) dos karton dan b) karung plastik (cara petani). Anak petak terdiri dari 2 faktor yaitu disekat dan tidak disekat dan anak-anak petak adalah pelilinan terdiri dari 2 faktor yaitu dililin dan tidak dililin. Pengamatan dilakukan pada saat sebelum dikirim di Makassar dan setelah diangkut di Bogor. Pengamatan dilakukan terhadap berat buah, lingkar buah, kadar gula, kadar asam dan vitamin $\mathrm{C}$.

Data yang dikumpulkan antara lain data fisik, kimia dan organoleptik. Data fisik antara lain bobot buah (gram), lingkar buah $(\mathrm{cm})$. Sedangkan data kimia adalah kadar asam dan vitamin C dengan metode titrasi (AOAC, 1984) dan kadar gula (metode brix). Data ditabulasi, dilanjutkan dengan uji rancangan secara statistik dan dilanjutkan dengan uji Duncan.

(bobot awal - bobot akhir)

\% Susut bobot = ---------------------------- X 100\%

Bobot awal 


\section{HASIL DAN PEMABAHASAN}

\section{Pengaruh kemasan dan sekatan terhadap kualitas fisik dan kimia buah pamelo setelah pengangkutan}

Menurut Winarno (2004) pengemasan bertujuan untuk mengawetkan makanan, yaitu mempertahankan mutu kesegaran, warnanya tetap, untuk menarik konsumen, memberikan kemudahan penyimpanan dan distribusi. Disamping itu kemasan dapat menekan peluang terjadinya kontaminasi dari udara, air dan tanah, baik oleh mikroorganisme pembusuk, mikroorganisme membahayakan kesehatan maupun bahan kimia yang merusak atau racun.

Pengaruh kemasan dan sekatan terhadap kualitas fisik dan kimia dapat dilihat pada Tabel 1 .

Tabel 1. Persentase perubahan kualitas fisik dan kimia pada perlakuan kemasan dan sekatan sebelum dan sesudah pengangkutan

\begin{tabular}{llllll}
\hline \multicolumn{1}{c}{ Perlakuan } & $\begin{array}{c}\text { Susut } \\
\text { bobot }(\%)\end{array}$ & $\begin{array}{c}\text { Lebar } \\
\text { buah } \\
(\mathrm{cm})\end{array}$ & $\begin{array}{c}\text { Kadar } \\
\text { vitamin C } \\
(\%)\end{array}$ & $\begin{array}{c}\text { Kadar } \\
\text { asam }(\%)\end{array}$ & $\begin{array}{c}\text { Kadar gula } \\
\left(\text { Brix }^{\circ}\right)\end{array}$ \\
\hline Dos karton + sekat & $1,76 \mathrm{~b}$ & $14,5 \mathrm{~b}$ & $34,36 \mathrm{ab}$ & $65,60 \mathrm{a}$ & $8,85 \mathrm{~b}$ \\
\hline $\begin{array}{l}\text { Dos karton + tanpa } \\
\text { sekat }\end{array}$ & $3,42 \mathrm{ab}$ & $27,9 \mathrm{ab}$ & $26,64 \mathrm{bc}$ & $58,86 \mathrm{a}$ & $24,60 \mathrm{a}$ \\
\hline Karung + sekat & $2,88 \mathrm{ab}$ & $33,3 \mathrm{a}$ & $24,37 \mathrm{c}$ & $62,72 \mathrm{a}$ & $8,67 \mathrm{~b}$ \\
\hline Karung + tanpa sekat & $3,90 \mathrm{a}$ & $37,2 \mathrm{a}$ & $38,75 \mathrm{a}$ & $65,63 \mathrm{a}$ & $21,36 \mathrm{a}$ \\
\hline
\end{tabular}

Keterangan : Angka yang diikuti huruf yang sama pada kolom yang sama tidak berbeda nyata pada uji jarak berganda Duncan $a=0,05$

Pada Tabel 1 diketahui bahwa ada perubahan nyata dari beberapa parameter kualitas dari tempat produsen jeruk pamelo di Makassar hingga Bogor. Susut bobot yang paling tinggi adalah jeruk yang dikemas dengan karung tanpa disekat $(3,90 \%)$ dan berbeda nyata dengan perlakuan lainnya dan buah makin melebar (gepeng) karena saling berbenturan. Sedangkan kadar vitamin C, kadar asam dan kadar gula tidak berbeda nyata pada semua perlakuan. Hal ini sesuai dengan hasil penelitian Nofriati dan Asni (2015), dimana susut bobot jeruk siam lebih tinggi pada perlakuan kemasan karung jala plastik pada berbagai tingkat kematangan buah. Hal ini diakibatkan karena kemasan karung jala plastik merupakan kemasan yang terbuka sehingga penguapan lebih besar sehingga bobot buah juga semakin besar dan mengakibatkan kulit buah dapat berkeriput. Menurut pendapat Lara et.al., (2013) bahwa kulit buah yang berkeriput selama penyimpanan dan pengangkutan dapat mempengaruhi susut buah dimana kulit buah yang berkeriput tidak dapat mencegah kehilangan kadar air pada buah.

Berbeda dengan pengemasan jeruk keprok Tejakula asal Bali yang diangkut ke Jakarta dengan mobil, hanya rusak mekanis 2-3,6\% bila dikemas dengan kemasan kayu kapasitas $20 \mathrm{~kg}$, sedangkan dengan kemasan keranjang bambu kapasitas $8 \mathrm{~kg}$ memiliki kerusakan 3,41-3,75\% (Sabari dan Poernomo, 1985). Kemasan yang cocok untuk jeruk valensia segar, baik untuk angkutan jarak sedang $(1000 \mathrm{~km})$ maupun jarak jauh $(2000 \mathrm{~km})$ dengan mobil adalah kemasan modifikasi rakyat dengan kapasitas $34-38 \mathrm{~kg}$, yang buah jeruknya dicuci dahulu dengan bersih, diangin-anginkan dan dilap dengan kain planel halus, lalu 
disusun dalam kemasan yang sudah dilapisi kertas kraft sebagai beban pelapis wadah dengan model susunan 3-3 susunan buah menurut panjang dasar wadah, 4 layers susunan buah menurut panjang dasar wadah (Soedibyo, 1991).

Dari hasil pengamatan jeruk secara fisik pada kemasan karung plastik tidak ada buah yang tidak rusak selama pengangkutan, sehingga kemasan karung plastik tanpa sekat tidak dianjurkan karena buah menjadi rusak sampai di Bogor.

\section{Pengaruh Kemasan Dan Pelilinan Terhadap Kualitas Fisik Dan Kimia Buah Pamelo Setelah Pengangkutan}

Tabel 2. Persentase perubahan kualitas fisik dan kimia pada perlakuan kemasan dan pelilinan sebelum dan setelah pengangkutan.

\begin{tabular}{lccccc}
\hline \multicolumn{1}{c}{ Perlakuan } & $\begin{array}{c}\text { Susut } \\
\text { bobot }(\%)\end{array}$ & $\begin{array}{c}\text { Lebar } \\
\text { buah } \\
(\mathrm{cm})\end{array}$ & $\begin{array}{c}\text { Kadar } \\
\text { vitamin C } \\
(\%)\end{array}$ & $\begin{array}{c}\text { Kadar } \\
\text { asam (\%) }\end{array}$ & $\begin{array}{c}\text { Kadar gula } \\
\left(\text { Brix }^{\circ}\right)\end{array}$ \\
\hline Dos karton + Lilin & $1,95 \mathrm{~b}$ & $19,3 \mathrm{a}$ & $24,02 \mathrm{a}$ & $68,74 \mathrm{a}$ & $11,79 \mathrm{~b}$ \\
\hline $\begin{array}{l}\text { Dos karton + tanpa } \\
\text { Lilin }\end{array}$ & $2,39 \mathrm{~b}$ & $32,4 \mathrm{a}$ & $39,85 \mathrm{a}$ & $61,96 \mathrm{~b}$ & $22,28 \mathrm{a}$ \\
\hline Karung + Lilin & $2,69 \mathrm{~b}$ & $28,5 \mathrm{a}$ & $34,71 \mathrm{a}$ & $59,57 \mathrm{~b}$ & $5,74 \mathrm{~b}$ \\
\hline Karung + tanpa Lilin & $4,94 \mathrm{a}$ & $32,7 \mathrm{a}$ & $25,53 \mathrm{a}$ & $62,54 \mathrm{~b}$ & $23,68 \mathrm{a}$ \\
\hline
\end{tabular}

Keterangan : Angka yang diikuti huruf yang sama pada kolom yang sama tidak berbeda nyata pada uji jarak berganda Duncan $a=0,05$

Dari Tabel 2 diketahui bahwa susut bobot paling tinggi adalah perlakuan kemasan karung dan tanpa pelilinan. Soedibyo (1991) melaporkan bahwa jeruk valensia asal Lembang mengalami susut bobot setelah mengalami goncangan horisontal dan vertikal. Makin lama goncangan diterima, maka makin besar susut bobotnya. Goncangan horisontal menimbulkan susut bobot maupun kerusakan mikrobiologis yang lebih besar daripada goncangan vertikal.

Perlakuan jeruk tanpa pelilinan mengakibatkan buah jeruk cepat mengalami penurunan kualitas. Helmiyesi et al., (2008) mengemukakan bahwa jeruk siam tanpa perlakuan apapun selama penyimpanan mengalami penurunan kualitas yang ditandai oleh turunnya kadar vitamin $\mathrm{C}$ dan menurunnya kadar gula pada penyimpanan 15 hari.

Perlakuan yang terbaik adalah kemasan dos karton yang disekat dan dililin dengan susut bobot terkecil (1,76 - 1,95\%), lebar buah normal $(14,5-19,3 \mathrm{~cm})$, kandungan vitamin $C$ paling tinggi $(24,02-34,36 \%)$, kadar asam $(65,00$ $68,74 \%)$ dan kadar gula tinggi $(8,85-11,79$ Brix $)$. Pemberian lapisan lilin pada buah jeruk dapat mencegah terjadinya kerusakan fisik dan kimiawi sehingga dapat mempertahankan kesegaran buah jeruk pamelo pangkep. Hal ini sesuai dengan pendapat Baldwin et.al., (2012) bahwa penggunaan lapisan lilin ataupun lapisan edible dapat digunakan pada buah untuk mencegah kerusakan pasca panen sekaligus untuk mempertahankan umur simpan buah akibat laju respirasi dan transpirasi. 


\section{Pengaruh Kemasan, Sekatan Dan Pelilinan Terhadap Kualitas Organoleptik Buah Jeruk Pamelo Sebelum Dan Setelah Pengangkutan}

Tabel 3. Pengaruh kemasan, sekatan dan pelilinan terhadap kualitas organoleptik buah jeruk Pamelo sebelum pengangkutan.

\begin{tabular}{lccc}
\hline \multirow{2}{*}{ Perlakuan } & \multicolumn{3}{c}{$\begin{array}{c}\text { Sebelum Pengangkutan (\% jumlah } \\
\text { panelis) }\end{array}$} \\
\cline { 2 - 4 } & $\begin{array}{c}\text { Rasa } \\
\text { jeruk }\end{array}$ & $\begin{array}{c}\text { Aroma } \\
\text { jeruk }\end{array}$ & $\begin{array}{c}\text { Penampilan kulit } \\
\text { jeruk }\end{array}$ \\
\cline { 2 - 4 } & Suka & Suka & Suka \\
\hline Dos + disekat +dililin & 100 & 100 & 100 \\
Dos + disekat + tidak dililin & 100 & 100 & 100 \\
Dos + tidak disekat + dililin & 100 & 100 & 100 \\
Dos + tidak disekat + tidak dililin & 100 & 100 & 100 \\
\hline Karung + disekat +dililin & 100 & 100 & 100 \\
Karung + disekat + tidak dililin & 100 & 100 & 100 \\
Karung + tidak disekat + dililin & 100 & 100 & 100 \\
Karung + tidak disekat + tidak & 100 & 100 & 100 \\
dililin & & &
\end{tabular}

Keterangan : Angka yang diikuti huruf yang sama pada kolom yang sama tidak berbeda nyata pada uji jarak berganda Duncan $a=0,05$

Pada Tabel 3 terlihat bahwa pada saat sebelum pengangkutan, rasa jeruk, aroma dan penampilan masih disukai oleh seluruh panelis $(100 \%)$. Setelah pengangkutan dengan jasa Pos Indonesia terjadi penurunan tingkat kesukaan. Perlakuan yang masih disukai oleh panelis setelah pengangkutan adalah jeruk pamelo yang dikemas dalam dos, disekat tanpa pelilinan, karung disekat baik dililin maupun tanpa dililin dengan tingkat kesukaan 55\%.

Tabel 4. Pengaruh kemasan, sekatan dan pelilinan terhadap kualitas organoleptik buah jeruk Pamelo setelah pengangkutan

\begin{tabular}{lccc}
\hline \multirow{2}{*}{ Perlakuan } & \multicolumn{3}{c}{ Setelah Pengangkutan (\% jumlah panelis) } \\
\cline { 2 - 4 } & $\begin{array}{c}\text { Rasa } \\
\text { jeruk }\end{array}$ & $\begin{array}{c}\text { Aroma } \\
\text { jeruk }\end{array}$ & $\begin{array}{c}\text { Penampilan kulit } \\
\text { jeruk }\end{array}$ \\
\cline { 2 - 4 } & $\begin{array}{c}\text { Suka } \\
\text { Suka }\end{array}$ & Suka \\
\hline Dos + disekat +dililin & $37,50 \mathrm{~b}$ & $67,50 \mathrm{a}$ & $75,00 \mathrm{a}$ \\
Dos + disekat + tidak dililin & $55,00 \mathrm{a}$ & $80,00 \mathrm{a}$ & $67,50 \mathrm{~b}$ \\
Dos + tidak disekat + dililin & $17,50 \mathrm{c}$ & $82,50 \mathrm{a}$ & $70,00 \mathrm{a}$ \\
Dos + tidak disekat + tidak & $55,00 \mathrm{a}$ & $85,00 \mathrm{a}$ & $40,00 \mathrm{c}$ \\
dililin & & & \\
\hline Karung + disekat +dililin & $55,00 \mathrm{a}$ & $67,50 \mathrm{a}$ & $35,00 \mathrm{c}$ \\
Karung + disekat + tidak dililin & $55,00 \mathrm{a}$ & $82,50 \mathrm{a}$ & $35,00 \mathrm{c}$ \\
Karung + tidak disekat + dililin & $37,50 \mathrm{~b}$ & $67,50 \mathrm{a}$ & $40,00 \mathrm{c}$ \\
Karung + tidak disekat + tidak & $17,50 \mathrm{c}$ & $80,00 \mathrm{a}$ & $35,00 \mathrm{c}$ \\
dililin & & & \\
\hline
\end{tabular}

Keterangan : Angka yang diikuti huruf yang sama pada kolom yang sama tidak berbeda nyata pada uji jarak berganda Duncan a $=0,05$. 
Aroma jeruk masih tetap baik setelah pengangkutan dan tidak berbeda nyata untuk semua perlakuan dengan tingkat kesukaan 67,5 \% - 85,00 \%. Penampilan yang paling disukai panelis setelah pengangkutan adalah perlakuan pelilinan yang dikemas dalam dos baik disekat maupun tidak disekat. Kemasan dengan menggunakan dos dapat melindungi buah jeruk dari berbagai benturan fisik secara langsung. Hal ini sesuai dengan pendapat Nofriati dan Asni (2015) bahwa upaya untuk mempertahankan kesegaran buah jeruk yaitu dengan memperhatikan jenis kemasan yang digunakan. Kemasan kardus dan keranjang plastik merupakan kemasan terbaik dalam melindungi buah jeruk dibandingkan kemasan karung jala plastik selama penyimpanan.

\section{KESIMPULAN}

Perlakuan yang terbaik pada buah jeruk Pamelo setelah pengangkutan dari Makassar ke Bogor adalah kemasan dos karton yang disekat dan dililin dengan susut bobot terkecil (1,76 - 1,95\%), lebar buah normal $(14,5-19,3 \mathrm{~cm})$, kandungan vitamin $\mathrm{C}$ paling tinggi $(24,02-34,36 \%)$, kadar asam $(65,00$ $68,74 \%)$ dan kadar gula tinggi $\left(8,85-11,79 \mathrm{Brix}^{\circ}\right)$. Perlakuan yang masih disukai rasanya oleh panelis setelah pengangkutan adalah jeruk pamelo yang dikemas dalam dos, disekat tanpa pelilinan, karung disekat baik dililin maupun tanpa dililin dengan tingkat kesukaan 55\%. Aroma jeruk masih tetap baik setelah pengangkutan dan tidak berbeda nyata untuk semua perlakuan dengan tingkat kesukaan $67,5 \%-85,00 \%$. aroma jeruk masih tetap baik setelah pengangkutan dan tidak berbeda nyata untuk semua perlakuan dengan tingkat kesukaan 67,5 $\%$ - 85,00 \%. Penampilan yang paling disukai panelis setelah pengangkutan adalah perlakuan pelilinan yang dikemas dalam dos baik disekat maupun tidak sekat.

\section{DAFTAR PUSTAKA}

AOAC. 1984. Official Methods of Analysis on The Association of Official Agricuture Chemist. Assoc. Of Agric. Chem. Washington. D.C.

Armiati. 2010. Kelayakan finansial usahatani jeruk Pamelo di Kabupaten Pangkep. Jurnal Agrisistem, vol. 6 No. 2: $59-68$.

Baldwin E.A., Hagenmaier, R.D and Bai J., 2012. Edible Coatings and Films to Improve Food Quality. Second Edition. CRC Press, Taylor \& Francis Group.

Dinas Tanaman Pangan dan Peternakan Kabupaten Pangkep. 2010. Selayang pandang Komoditas Andalan Jeruk Besar Pangkep. Dinas Tanaman Pangan dan Peternakan Kabupaten Pangkep.

Jeruk Besar Pangkep Kabupaten Pangkep. Dinas Tanaman Pangan dan Peternakan Kabupaten Pangkep.

Helmiyesi, Hastuti R.B., dan Prihastanti, E., 2008. Pengaruh Lama Penyimpanan Terhadap Kadar Gula dan Vitamin C pada Buah Jeruk Siam (Citrus nobilis var. microcarpa ). Buletin Anatomi dan Fisiologi. 16 (2):33-37

Lara I, Burcu Belge, Luis F Goulou, 2013. The Fruit Cuticle As A Modular Of Postharvest Quality. J. Postharvest Biology and Technologi. 87:103-112.

Mihindukulasuriya S.D.F., and Lim LT. 2014. Nanotechnology development packaging: A review. J. Food Science \& Technology. 2014; 40 (2) :149-167 
Nofriati, D., dan Asni N. 2015. Pengaruh Jenis Kemasan dan Tingkat Kematangan Terhadap Kualitas Buah Jeruk Selama Penyimpanan. Jurnal Penelitian Pascapanen Pertanian. 12 (2) : 37-42.

Sabari dan Poernomo. 1985. Handling Trial of Citrus Fruit Var. Keprok TejakulaBali to Jakarta. Paper Sub-mitted on the XVII Horticulture working group meeting on 3-6 September 1985 at Lembang.

Soedibyo, M. 1988. Mempelajari Proses Penguningan Jeruk Manis (citrus sinensis 1. Osbeck) Dengan Gas Asetilen. Penel. Hort. 3 (1) : 92-98.

1991. Pengemasan dan Pengangkutan Jeruk Valensia (Citrus sinensis L. Osbeck) dengan Mobil. Jurnal Hort. 1(2):49-53.

Winarno F.G. 2004. Kimia Pangan dan Gizi. PT Gramedia Pustaka Utama.

Jakarta 